\title{
Torsional and Shear Wind Loads on Flat-Roofed Buildings
}

\author{
Mohamed Elsharawy, Khaled Galal, Ted Stathopoulos \\ Faculty of Engineering and Computer Science, Concordia University, Montréal, Québec, Canada
}

\begin{abstract}
There is limited information available on wind-induced torsional loads on buildings. This paper presents results of wind tunnel tests carried out on a series of models of low- and medium-rise buildings. Four buildings with the same plan dimensions but different heights $(6,12,25$ and $50 \mathrm{~m})$ were tested in a simulated open terrain exposure for different wind directions. Synchronized wind pressure measurements allowed estimating instantaneous base shear forces and torsional moments on the tested rigid building models. Results were normalized and presented in terms of mean and peak values of shear and torsional coefficients for two load cases, namely: maximum torsion and corresponding shear, and maximum shear and corresponding torsion. Comparison of the wind tunnel test results with current torsionand shear-related provisions in the American Standard as well as the Canadian and European codes demonstrates significant discrepancies. The findings of this study could assist wind code and standards committees to improve provisions for wind-induced torsional loads on buildings.
\end{abstract}

Key words: codes, low-rise building, medium-rise buildings, torsion, wind load. 


\section{INTRODUCTION}

The wind flow characteristics (i.e. attached flow, separation and reattachment) around buildings are critical for the determination of wind forces for building design. Along-wind force fluctuations are mainly generated by approaching flow turbulence, but the fluctuations in across-wind force and torsion are generally dominated by vortex shedding [1], at least for medium-rise buildings. The recent trend towards more complex building shapes and structural systems results in more unbalanced wind loads and larger torsional moments. Thus, re-visiting the wind load provisions is of utmost concern to ensure their adequacy in evaluating torsion on buildings and, consequently, achieve safe yet economic building design. In fact, most of the wind loading provisions on torsion have been developed from the research work largely directed towards very tall and flexible buildings [2 - 7] for which resonant responses are very significant. However, the dynamic response of most medium-rise buildings is dominated by quasi-steady gust loading with little resonant effect. The limited knowledge regarding wind-induced torsion is apparent in the international wind loading codes and standards uses different approaches in evaluating torsion loads on buildings. Recently, Tamura et al. [8] and Keast et al. [9] studied wind load combinations including torsion for medium-rise buildings. Although the latter study concluded that for rectangular buildings the peak overall torsion occurs simultaneously with $30-40 \%$ of the peak overall shear, it should be noted that this observation conclusion was drawn based on testing a limited number of building models. Additional experimental results from testing different building configurations are still needed in order to confirm and generalize such observations.

Furthermore, studies on wind-induced torsional loads on low-rise buildings are very limited. Isyumov and Case [10] measured wind-induced torsion for three low-rise buildings with 
different aspect ratios (length/width $=1,2$, and 3) in open terrain exposure as modeled in the wind tunnel. It was suggested that applying partial wind loads, similar to those implemented for the design of medium-rise buildings, would improve the design of low-rise buildings until more pertinent data becomes available. Tamura et al. [11] examined correlation of torsion with along-wind and across-wind forces for rectangular low-rise buildings tested in simulated open and urban terrain exposures. Low-rise buildings of different roof slopes were tested by Elsharawy et al. [12] but peak torsions evaluated by current wind provisions were found to be different from the measured peak torsion in the wind tunnel.

This study reports the analysis and code comparison of results from additional measurements carried out in a boundary layer tunnel to investigate shear forces occurring simultaneously with maximum torsion, as well as maximum shears and corresponding torsions on flat-roof buildings of different heights. Results of the study are important for better evaluation of windinduced torsional loads on low- and medium-rise buildings. Some preliminary results of this research have appeared in Elsharawy et al. [13].

\section{WIND-INDUCED TORSION IN CURRENT WIND CODES AND STANDARDS}

ASCE 7 [14] specifies wind loads on low-rise buildings (defined as having mean roof height, $\mathrm{h}<18 \mathrm{~m}$ and $\mathrm{h}<$ smallest horizontal building dimension, $\mathrm{B})$ and medium-height rigid buildings, defined as having lowest natural frequency, $\mathrm{f}_{\mathrm{n}}>1 \mathrm{~Hz}$. On the other hand, NBCC [17] identifies low-rise buildings ( $\mathrm{h}<10 \mathrm{~m}$, or $\mathrm{h}<20 \mathrm{~m}$ and $\mathrm{h}<\mathrm{B}$ ) and medium-rise rigid buildings ( $\mathrm{h}<60 \mathrm{~m}, \mathrm{~h} / \mathrm{B}<4, \mathrm{f}_{\mathrm{n}}>1 \mathrm{~Hz}$ ). In EN 1991-1-4 [16], low-rise buildings are defined as those with $\mathrm{h}<15 \mathrm{~m}$ while buildings with frames, structural walls with $\mathrm{h}<100 \mathrm{~m}$ are 
introduced structurally as rigid buildings. Wind-induced torsion is treated differently in these standards.

\section{Low-rise buildings}

Wind loads on low-rise buildings have not received sufficient attention, particularly when the large investment in such structures is considered. Wind loads generally govern the design of lateral structural systems of low-rise buildings in low seismicity areas and where there is high probability of occurrence of severe wind events. The development of provisions for the evaluation of wind loads on low-rise buildings was based on the research carried out at the University of Western Ontario in the late 70's, when an extensive experimental program in a boundary layer wind tunnel considered a variety of rectangular low-rise buildings with different dimensions, roof slopes and upstream terrain exposures [17-18]. However, windinduced torsional loads were not examined in detail. ASCE 7 [14] introduces two load cases in the envelope method to estimate torsion, namely; maximum torsion with corresponding shear and maximum shear with corresponding torsion. NBCC [15] specifies one load case in the static method assigned for low-rise buildings to evaluate maximum shear as well as maximum torsion.

For comparison purposes, three low-rise buildings with flat roofs (width, B =16 $\mathrm{m}$ and height, $\mathrm{h}=12 \mathrm{~m})$ having horizontal aspect ratios $(\mathrm{L} / \mathrm{B}=1,2$, and 3) located in an open terrain exposure have been analyzed by American, Canadian and European codes and standards. Both envelope and static methods stated in the ASCE 7 [14] and NBCC [15] were applied for the studied low-rise buildings, in addition to the analytical method specified for all building heights in EN 1991-1-4 [16]. In the envelope method (ASCE 7 [14]), the external pressure coefficients $\left(\mathrm{GC}_{\mathrm{pf}}\right)$ on building envelope are estimated for low-rise buildings using figure 
28.4-1 and the directionality factor $\left(\mathrm{K}_{\mathrm{d}}\right)$ was taken as 1 . The torsional load case was specified by removing $75 \%$ of the full wind load on half of building surfaces, as indicated in figure 28.4-1 (ASCE 7 [14]). As for the static method of NBCC [15], the external peak pressure coefficients $\left(\mathrm{C}_{\mathrm{g}} \mathrm{C}_{\mathrm{p}}\right)$ are provided for low-rise buildings in figure I-7 of Commentary I. Calculations were carried out considering open terrain exposure. Static method values were increased by $25 \%$ to eliminate the implicit reduction $(0.8)$ due to directionality issue. Similarly, for EN 1991-1-4 [16], the external pressure coefficients for vertical walls of rectangular plan buildings are calculated using figure 7.5 and table 7.1 available in section 7 . The non-uniform distribution of wind loads were simulated by applying triangular load (EN 1991-1-4 [16]). The wind velocity was adjusted by using the well-known Durst curve given in the ASCE 7 [14] Commentary, figure C26.5.1. All ASCE 7 [14] values were multiplied by $1.51^{2}$ and EN 1991-1-4 [16] values by $1.06^{2}$ in order to consider the effect of the 3 -sec and the 10-min wind speed respectively in comparison to the mean-hourly wind speed in NBCC [15].

The results were presented in terms of shear and torsion coefficients and equivalent eccentricity. The shear coefficient, torsional coefficient and equivalent eccentricity in transverse direction were estimated as per Eqs. 1, 2 and 3, respectively, where $q_{h}$ is the dynamic wind pressure at building mean roof height:

$$
\begin{aligned}
\mathrm{C}_{\mathrm{V}} & =\frac{\text { Base shear force }}{\mathrm{q}_{\mathrm{h}} \mathrm{Bh}} \\
\mathrm{C}_{\mathrm{T}} & =\frac{\text { Base torsional moment }}{\mathrm{q}_{\mathrm{h}} \mathrm{Bh} \mathrm{L}}
\end{aligned}
$$




$$
\mathrm{e}(\%)=\frac{\text { Base torsional moment }}{\text { Base shear force } * \mathrm{~L}} 100
$$

Fig. 1 presents the results for torsional loads evaluated by ASCE 7 [14], NBCC [15], and EN 1991-1-4 [16] for the three low-rise buildings. As can be clearly seen, significant differences are found among the three national codes/standards in evaluating the torsional moment. For building with an aspect ratio (L/B) of 3, NBCC [15] estimates torsion which is hardly equal to one third of the ASCE 7 [14] and EN 1991-1-4 [16]. The distribution of wind loads introduced in torsional load case is very different in these codes. ASCE 7 [14] introduces equivalent eccentricity that is approximately $18 \%$ of the building length while NBCC [15] and EN 1991-1-4 [16] have eccentricities of about 4\%, and 8\% of the building length, as Fig. 1 shows. Clearly, NBCC [15] provides significantly lower values for the torsional moment on the three low buildings considered in this comparison.

\section{Medium-rise buildings}

The National Building Code of Canada was the first to adopt the effect of wind-induced torsional loads on buildings in its provisions. Since the early 70's and till 2005, the NBCC subcommittee on wind loads introduced the unbalanced wind loads or wind-induced torsion by removing $25 \%$ of the full wind load from any portion on building surfaces in order to maximize torsion according to the most critical design scenario states. This allowance for torsion is equivalent to applying the full design wind load at 3 or 4 percent of the building width. In the absence of detailed research in this area and based on some wind tunnel observations, the $25 \%$ removal of the full wind load has been modified in the NBCC 2005 
edition to a complete removal of the full wind loads from those areas that would lead to maximizing torsion. This allowance for torsion is equivalent to applying the full design wind load at 12.5 percent of the building width in case of loading half of the width of the building. On the other hand, the ASCE-7 subcommittee on wind loads has taken the initiative to add provisions for wind-induced torsional loads on buildings since the 1995 edition of the standard. These provisions were similar to the NBCC provisions at that time (i.e. removing $25 \%$ of the full wind loads on $50 \%$ of the projected area bounded by the extreme projected edge of the building). Since the 2002 edition, the torsional load case was characterized by applying $75 \%$ of the full wind load with equivalent eccentricity $15 \%$ of the building dimension. This allowance for torsion is equivalent to applying the full design wind load at 11.25 percent of the building width.

The current Australian standard [18] does not require wind-induced torsion to be considered in the design of rectangular buildings with heights lower than $70 \mathrm{~m}$. For buildings with heights greater than $70 \mathrm{~m}$, torsion shall be applied based on eccentricity of $20 \%$ of building width with respect to the center of geometry of the building on the along-wind loading. In EN 1991-1-4 [16], the non-uniform applied wind loads in torsional load case allow for torsional moment equivalent to applying the full design wind load with 6 percent eccentricity. Such differences in torsion provisions for medium-rise buildings in the current codes and standards are questionable. Furthermore, it is interesting to note that the torsional load case is always described in wind provisions on the basis of the full wind load case (shear load case). Whereas the fluctuating wind forces could indeed induce torsion even for rectangular buildings subjected to wind perpendicular to their facade. Therefore, the oversimplification 
for the shear load case in the wind provisions by neglecting the corresponding torsion and applying uniform wind loads needs to be examined.

Similar to the above-discussed low-rise building cases, Fig. 2 compares the code/standard provisions for three medium-rise buildings $(B=30 \mathrm{~m}, \mathrm{~h}=60 \mathrm{~m})$ with horizontal aspect ratios (L/B =1, 2, and 3) located in suburban terrain. For these buildings, the directional-part I method (ASCE 7 [14]) assigned for enclosed, partially enclosed, and open buildings of all heights was applied. The side wall external pressure coefficient $\left(\mathrm{C}_{\mathrm{p}}\right)$ was estimated according to figure 27.4-1. Suburban terrain exposure B was considered, with the directionality factor $\left(\mathrm{K}_{\mathrm{d}}\right)$ and the gust factor $(\mathrm{G})$ taken as 1 and 0.85 , respectively. Maximum torsion and corresponding shear were estimated by applying $75 \%$ of the full wind load and equivalent eccentricity of $15 \%$ of building width, as indicated in Case 2 in figure 27.4-8. The external pressure estimation by the simplified method (NBCC [15]) is taken from figure I-15, Commentary $\mathrm{I}$, and the gust factor $\left(\mathrm{C}_{\mathrm{g}}\right)$ was taken as 2. The partial load case was implemented by completely removing the full wind loads from half of building faces to estimate maximum torsion and corresponding shear as specified in Case B in figure I-16, Commentary I. In the Eurocode 2005 [16], the same approach used for low-rise buildings has been applied for medium-rise buildings. The terrain factor roughness $\left(\mathrm{C}_{\mathrm{r}}\right)$ was calculated for terrain category III, which is expressed in Eurocode 2005 [16] as a peer for the suburban terrain exposure.

From the Figure it can be clearly seen that the NBCC [15] estimates torsional coefficient $40 \%$ and $60 \%$ higher than the values in the ASCE 7 [14] and the EN 1991-1-4 [16], whereas the corresponding shear in the three design provisions are different. Moreover, significant differences of equivalent eccentricities imply significant differences in wind load 
distributions. Applying different loads with different eccentricities results in different torsional moments. Such discrepancies in definition of the torsional loads in the three codes/standards -in addition to neglecting torsion totally in some other international codes/standards- highlight the urgent need for examining experimentally, the wind-induced torsion and shear on low- and medium-rise buildings.

\section{EXPERIMENTAL PROCEDURE}

The current study used a low-rise building model with full-scale equivalent horizontal dimensions $61 \times 39 \mathrm{~m}$. These particular building dimensions were used because data on windinduced pressures and forces (but not torsion) were available from previous studies, thus comparisons would be more convenient and meaningful. Then, an extension part was manufactured and connected to the low rise-building model to test medium-rise buildings, as it can be seen in Fig. 3. The building model was tested at different heights, by sliding it downwards in a precise tightly fit slot in the turntable, such that it represents four actual buildings with heights $6,12,25$ and $50 \mathrm{~m}$. Model dimensions and the tested building heights are given in Table 1. In this study, all tested buildings were assumed to be structurally rigid and follow the limitations stated in the three wind load standards. Buildings were tested in open terrain exposure for different wind directions. The experiments were carried out in the boundary layer wind tunnel of Concordia University. The working section of the tunnel is approximately $12.2 \mathrm{~m}$ length $\mathrm{x} 1.80 \mathrm{~m}$ width. Its height is adjustable and ranging between 1.4 and $1.8 \mathrm{~m}$ to maintain negligible pressure gradient along the test section. A turntable of $1.2 \mathrm{~m}$ diameter is located on the test section of the tunnel and allows testing of models for any wind direction. An automated Traversing Gear system provides the capability of measuring wind characteristics at any spatial location around a building model inside the test section. A 
geometric scale of 1:400 has been recommended for the simulation of the most important variables of the atmospheric boundary layer under strong wind conditions. An open terrain exposure was simulated in the wind tunnel. The 1:400 tallest building model was equipped by 146 pressure taps on its side walls. The flat roof does not have any pressure taps since uplift forces do not contribute to torsion or horizontal shear forces. Focus was directed towards the effect of building height and wind directions on the wind-induced torsional loading, as it is believed that would be very useful for the structural engineering community.

Fig. 4 shows the approach flow profiles of mean wind velocity and turbulence intensity measured using a 4-hole Cobra probe (TFI) for the simulated terrain exposure. The wind velocity at free stream was $13.6 \mathrm{~m} / \mathrm{s}$. The power law index $\alpha$ of the mean wind velocity profile was set at $\alpha=0.15$. Typical spectra of the longitudinal turbulence component measured by Stathopoulos [20] at one sixth of the boundary layer depth are compared with the well-known Von Karman's equation and Davenport's empirical expression - see Fig. 5. The length scale of the turbulence in the longitudinal direction was estimated as $112 \mathrm{~m}$. The length scale of the turbulence is larger than the largest building dimension such that the wind waves enforce the entire building producing a quasi-static response. Although it is not common for medium height buildings to be situated in open terrain exposure, this exposure was chosen as a kind of conservatism since higher loads are expected to act on the tested buildings in this case.

The pressure measurements on the models were conducted using a system of miniature pressure scanners from Scanivalve (ZOC33/64Px) and the digital service module DSM 3400. All measurements were synchronized with a sampling rate of $300 \mathrm{~Hz}$ on each channel for a period of $27 \mathrm{sec}$ (i.e. about one hour in full scale). As the tubing system was used in these 
measurements, the Gain and Phase shifts of pressure signals due to Helmholtz's resonance effects were corrected by using traditional restrictors. It is well known that the mean wind speed has the tendency to remain relatively steady over smaller periods of time (i.e. 10 minutes to an hour) assuming stationarity of wind speed, as reported by van der Hoven [21]. It is also worthy to mention that this period is considered suitable to capture all gust loads, associated with the fundamental building frequencies, which may be critical for structural design. The peak shear and torsional coefficients were considered as the average of the maximum ten values picked up from a 1-hr full-scale equivalent time history of the respective signal. This approach has been considered a good approximation (as a lower boundary) to the mode value of detailed extreme value analysis and it has been used in several wind tunnel studies. Also the corresponding shear and torsion were evaluated as the average of ten values corresponding to the ten peaks.

\section{Analytical approach}

Fig. 6 shows a schematic representation of the external wind pressure distributions on the building at a certain instant, the exerted shear forces, $\mathrm{F}_{\mathrm{X}}$ and $\mathrm{F}_{\mathrm{Y}}$, along the two orthogonal axes of the buildings, as well as torsional moment, $\mathrm{M}_{\mathrm{T}}$, at the geometric centre of the building. Pressure measurements are scanned simultaneously. The instantaneous wind force at each pressure tap is calculated according to:

$\mathrm{f}_{\mathrm{i}, \mathrm{t}}=\left(\mathrm{p}_{\mathrm{i}, \mathrm{t}} \times \mathrm{A}_{\text {effective }}\right) \quad \mathrm{f}_{\mathrm{j}, \mathrm{t}}=\left(\mathrm{p}_{\mathrm{j}, \mathrm{t}} \times \mathrm{A}_{\text {effective }}\right)$ 
where $\mathrm{p}_{\mathrm{i}, \mathrm{t}}$, and $\mathrm{p}_{\mathrm{j}, \mathrm{t}}$ are instantaneous pressures measured at each pressure tap. Aeffective is the tributary area per each pressure tap. The wind forces exerted at pressure tap locations in Xand $\mathrm{Y}$-directions are noted by $\mathrm{f}_{\mathrm{i}, \mathrm{t}}$ and $\mathrm{f}_{\mathrm{j}, \mathrm{t}}$, respectively. For each wind direction, the horizontal force components in $\mathrm{X}$ - and $\mathrm{Y}$-directions and the total base shear are evaluated according to:
$F_{X}=\sum_{i=1}^{N} f_{i, t}$
$F_{Y}=\sum_{j=1}^{M} f_{j, t}$
$\mathrm{V}=\sqrt{\mathrm{F}_{\mathrm{X}}^{2}+\mathrm{F}_{\mathrm{Y}}^{2}}$

where $\mathrm{N}$ and $\mathrm{M}$ are the numbers of pressure taps on the longitudinal and transverse directions, respectively. $\mathrm{V}$ is the resultant shear wind force. Also, the torsional moment $\left(\mathrm{M}_{\mathrm{T}}\right)$ was estimated as follows:

$\mathrm{M}_{\mathrm{T}}=\sum_{\mathrm{i}=1}^{\mathrm{N}} \mathrm{f}_{\mathrm{i}, \mathrm{t}} * \mathrm{r}_{\mathrm{i}}+\sum_{\mathrm{j}=1}^{\mathrm{M}} \mathrm{f}_{\mathrm{j}, \mathrm{t}} * \mathrm{r}_{\mathrm{j}}$

where $r_{i}$ and $r_{j}$ are the distances between the pressure taps and the building center in $X-$ and Y-directions, respectively.

All these forces are normalized with respect to the dynamic wind pressure at the roof height as follows:
$\mathrm{C}_{\mathrm{vx}}=\frac{\mathrm{F}_{\mathrm{X}}}{\mathrm{q}_{\mathrm{h}} \mathrm{Bh}}$
$\mathrm{C}_{\mathrm{vy}}=\frac{\mathrm{F}_{\mathrm{Y}}}{\mathrm{q}_{\mathrm{h}} \mathrm{Bh}}$
$\mathrm{C}_{\mathrm{V}}=\frac{\mathrm{V}}{\mathrm{q}_{\mathrm{h}} \mathrm{Bh}}$ 
where $q_{\mathrm{h}}=$ dynamic wind pressure at roof height $\left(\mathrm{kN} / \mathrm{m}^{2}\right), \mathrm{B}=$ smaller horizontal building dimension $(\mathrm{m})$, and $\mathrm{h}=$ mean roof building height $(\mathrm{m})$. The torsional coefficient, $\mathrm{C}_{\mathrm{T}}$, and equivalent eccentricity, e, are evaluated based on:

$\mathrm{C}_{\mathrm{T}}=\frac{\mathrm{M}_{\mathrm{T}}}{\mathrm{q}_{\mathrm{h}} \mathrm{BhL}} \quad \mathrm{e}(\%)=\frac{\mathrm{M}_{\mathrm{T}}}{\mathrm{LV}} \times 100$

where $\mathrm{L}=$ longer horizontal building dimension

\section{RESULTS OF THE WIND TUNNEL TESTS}

\section{Variation of torsion and shear coefficients}

Fig. 7 shows the variation of mean and peak shear coefficients $\left(\mathrm{C}_{\mathrm{vx}}, \mathrm{C}_{\mathrm{vy}}\right)$ with wind direction for the $6,12,25$, and $50 \mathrm{~m}$ buildings tested in simulated open terrain exposure. As expected, the shear coefficient in $\mathrm{X}$-axis decreases when the incident wind angle changes from $0^{\circ}$ to $90^{\circ}$. On the other hand, for the same wind range the shear coefficient in Y-axis increases. The maximum shear force in the $\mathrm{X}$-direction occurs for wind direction ranging from $0^{\circ}$ to $30^{\circ}$; whereas the maximum shear in the Y-direction occurs for wind that is almost perpendicular to the building face, (i.e. $90^{\circ}$ ). For the tested buildings, the peak shear coefficients increase by about $50 \%$ and $15 \%$ in the $\mathrm{X}$ - and Y-directions, respectively, upon increasing the building height from 6 to $50 \mathrm{~m}$.

Although determining the shear coefficient is important for proposing an equivalent wind load, identifying the horizontal distribution of these wind loads on the building's lateral load resisting systems requires quantifying the associated torsional moment on the building. The variation of the mean and peak torsional coefficients for different wind directions is presented 
in Fig. 8 for buildings with heights of 6, 12, 25, and $50 \mathrm{~m}$ in open terrain exposure. As a result of the building models having symmetric shapes, mean torsions are zero for wind directions perpendicular to building face, i.e. $0^{\circ}$ and $90^{\circ}$. However, there are significant maximum and minimum torsional coefficients for these wind directions due to the small instantaneous wind pressure correlation over the building envelope in the horizontal direction. From Fig. 8, it could be seen that the maximum torsional moment occurs for wind directions varying from $15^{\circ}$ to $45^{\circ}$ for the first three buildings $(6,12,25 \mathrm{~m})$ while for the $50 \mathrm{~m}$ building, two peaks occur at wind directions $30^{\circ}$ and $75^{\circ}$. This may be attributed to different characteristics of wind flow (i.e. the size of gusts and turbulence intensity) interactions with buildings with height lower than $25 \mathrm{~m}$ compared to higher buildings. Furthermore, the mean, the root mean square (RMS), and the peak factor (Max value / Mean value) were estimated for the fluctuating shear and torsion coefficients recorded for the critical wind directions and presented in Table 2 for all tested buildings.

\section{Most critical torsion and shear coefficients}

By definition, the distribution and the magnitude of wind forces on building envelope are related to the magnitude of torsional moment acting on the building. Therefore, based on the wind tunnel measurements, two load cases are presented; Case A shows maximum torsion $\left(\mathrm{C}_{\mathrm{T}}\right.$ Max. $)$ with corresponding shear $\left(\mathrm{C}_{\mathrm{V}}\right.$ Corr. $)$, while Case $\mathrm{B}$ shows maximum shear $\left(\mathrm{C}_{\mathrm{V}}\right.$ Max. $)$ with corresponding torsion $\left(\mathrm{C}_{\mathrm{T}}\right.$ Corr. $)$. There are two components for $\mathrm{C}_{\mathrm{V}}$, one in the $\mathrm{X}$ - and the other in the Y- direction. For simplicity, torsional loads can be treated analytically by introducing wind forces (V) with equivalent eccentricity (e), as shown in Fig. 9. Tables 3a and $3 \mathrm{~b}$ show these coefficients for the critical wind directions for which the maximum torsion and shear were measured for Case A and Case B, respectively. For the $50 \mathrm{~m}$ building height, 
the most critical torsional moments were recorded for wind directions $30^{\circ}$ and $75^{\circ}$. Thus, it is considered important for the wind provisions to cover these critical torsions for achieving proper design for low- and medium-rise buildings. These Tables also show that the maximum equivalent eccentricity was $15.3 \%$ of the building's largest horizontal dimension for the $50 \mathrm{~m}$ high building. The maximum ratio between the corresponding shear (associated with maximum torsion, Case A) to the maximum base shear (full load - Case B) was $74 \%$ for the $25 \mathrm{~m}$ high building. As has been reported in previous wind tunnel studies [4, 22-24], windinduced torsion always exists even for a wind direction that results in the maximum full shear force. The current study demonstrates that maximum shear is associated with equivalent eccentricities about 3\%, 6\% for low- and medium-rise buildings, respectively. This is in line with the following statement given in ASCE 7 [14], (Commentary part, C27.4.6),

"...wind tunnel studies often show an eccentricity of 5\% or more under full (not reduced) base shear. The designer may wish to apply this level of eccentricity at full wind loading for certain more critical buildings even though it is not required by the standard. The present more moderate torsional load requirements can in part be justified by the fact that the design wind forces tend to be upper-bound for most common building shapes.",

\section{COMPARISONS OF EXPERIMENTAL RESULTS WITH CODE PROVISIONS}

The results of the wind tunnel tests (Case A and Case B) for the tested building heights were also compared to the values for base shear force and torsional moment evaluated by ASCE 7 [14], NBCC [15] and EN 1991-1-4 [16].

\section{ASCE 7 [14]}


The three analytical procedures stated in ASCE 7 [14] to evaluate wind loads were applied for this comparison. The envelope method for low-rise buildings was used since the mean roof height $\mathrm{h}$ is less than $18 \mathrm{~m}$ and $\mathrm{h}$ is less than the least horizontal dimension (B). Also, figure 28.4-1 is used to get the external pressure coefficients $\left(G C_{p f}\right)$. The basic (transverse) and torsional load cases presented in ASCE 7 [14], figure 28.4-1 are used to estimate the maximum torsional moment and the maximum base shear. In ASCE 7 [14], directional methods, Part I proposed for all building heights and Part II recommended for buildings up to $48.8 \mathrm{~m}$ height, are also considered in this comparison. External pressure coefficients were collected from figure 27.4-1. Pressure coefficients are provided in table 27.6-1 for buildings with height up to $48.8 \mathrm{~m}$. ASCE 7 [14] calculations were carried out considering the open terrain exposure C. Also, the directionality factor was taken as 1. All values were multiplied by $1.51^{2}$ in order to relate the 3 -sec wind speed to the mean-hourly wind speed in the wind tunnel test. Fig. 10 summarizes the results for Case A (see Table 3a): it shows the peak torsional coefficients, corresponding shear, and equivalent eccentricity for the buildings tested in the wind tunnel study along with the corresponding ASCE 7 [14] design values. Although the directional methods (Part I and II) necessitate equivalent eccentricity 15\% which seems to be in relatively good agreement with the wind tunnel results, the ASCE analytical method estimates higher wind loads (i.e. corresponding shear) than those measured for the buildings tested in the wind tunnel. Consequently, the torsion evaluated by these two methods is significantly greater than the wind tunnel torsion. This is due to the fact that the directional methods in ASCE 7 [14] apply loads based on old wind tunnel tests, mainly on tall buildings without taking into account the load combination on different building surfaces. Aside from this conclusion, it could be said that for low-rise buildings, the envelope method 
of the ASCE 7 [14] shows relatively good agreement with the measured torsion, although decreasing the eccentricity from about $18 \%$ to $15 \%$ will improve its correlation with the wind tunnel test results, see Fig. 10.

\section{NBCC [15]}

In NBCC [15], the static method, as mentioned earlier, is introduced for low-rise buildings while the simplified method is proposed for rigid buildings with medium height. The static method calculations for the torsional and shear coefficients were derived based on figure I-7 of NBCC [15], Commentary I, where the external peak (gust) pressure coefficients $\left(C_{p} C_{g}\right)$ are provided for low buildings. Likewise, for the simplified method, the external pressure is taken from figure I-15, Commentary I. Partial and full load cases were considered to estimate maximum torsion and corresponding shear, as well as maximum shear and corresponding torsion. Calculations were carried out considering the open terrain exposure. Static method values were increased by $25 \%$ to eliminate the implicit reduction $(0.8)$ due to directionality and other factors. Fig. 11 shows the wind tunnel results along with the evaluated torsional load case parameters by the static and simplified methods in NBCC [13]. Although the static method requires applying higher loads $\left(\mathrm{C}_{\mathrm{v}}\right.$ Corr. $)$ in comparison with wind tunnel measurements, it significantly underestimates torsion $\left(\mathrm{C}_{\mathrm{T} \max }\right)$ on low-rise buildings. This is mainly due to the fact that it specifies a significantly lower equivalent eccentricity (e\%) which is just $3 \%$ of the facing building's width compared to the equivalent eccentricity evaluated in the wind tunnel tests (i.e. $14.2 \%$ and $13.3 \%$ for buildings with heights of 6 and $12 \mathrm{~m}$ respectively). On the other hand, the simplified method requires applying almost the same wind loads as those measured in the wind tunnel. The eccentricity specified by the simplified method is $25 \%$ of the facing building width, which is significantly higher than the measured 
eccentricity; hence the evaluated torsion using the simplified method exceeds the measured torsion significantly.

\section{EN 1991-1-4 [16]}

The Eurocode defines one unified analytical method that can be used for predicting the wind forces on all building types regardless of their height. All EN1991-1-4 [16] values were multiplied by $1.06^{2}$ in order to relate the 10 -min wind speed to the mean-hourly wind speed. Fig. 12 summarizes the results for Case A (see Table 3a). Peak torsional coefficients, corresponding shears, and equivalent eccentricities are evaluated either by the wind tunnel study or by the Eurocode 2005 [16]. Although the corresponding shear $\left(\mathrm{C}_{\mathrm{v}}\right.$ Corr. $)$ and eccentricities show discrepancies with the experimental results, the maximum torsion coefficients $\left(\mathrm{C}_{\mathrm{T} \text { Max. }}\right)$ agree well.

\section{TOWARDS ENHANCING THE CURRENT TORSION AND SHEAR PROVISIONS}

A comparison between the shear load case predicted using the provisions of three wind codes/standards, and that measured in the wind tunnel, is presented in Fig. 13. The shear load case, Case B (see Table 3b), maximum shear, corresponding torsion and equivalent eccentricity clearly indicates that the static and envelope methods for low buildings in NBCC [15] and ASCE 7 [14] succeed to predict well maximum shear forces on low-rise buildings. The corresponding torsion is also predicted adequately by the two methods (i.e. static and envelope) for low-rise buildings with heights lower than $12 \mathrm{~m}$. All other methods in the three sets of provisions overestimate shear forces on buildings and neglect fully the corresponding torsion. The shear force overestimation by codes and standards is probably due to the limited number of wind tunnel tests carried out for the purposes of codification and the lack of 
correlation of wind loads on different building surfaces which had not been considered in the early wind tunnel tests. However, the corresponding shear force associated with the maximum torsion which was measured in the wind tunnel and shown in Figures 10, 11 and 12 is about $75 \%$ of the maximum measured shear force presented in Fig. 13.

Torsional loads on buildings are sensitive to the aspect ratio and the shape of the structure, including its roof shape. Since the buildings tested in the current study are all with an aspect ratio $\mathrm{L} / \mathrm{B}=1.6$, it was important to combine the results with other data available in the literature towards generalizing the findings. Indeed, Tamura et al. [1] tested a low-rise building with aspect ratio of $\mathrm{L} / \mathrm{B}=1.4$ and with dimensions of $\mathrm{L}=42.5, \mathrm{~B}=30$ and $\mathrm{h}=12.5$ $\mathrm{m}$. The building was located in an open terrain exposure with $\alpha=0.15$. Following the same torsion and shear coefficient definitions stated in the current study, the maximum torsion coefficient $\left(\mathrm{C}_{\mathrm{T} \text { Max }}\right)$ was reported to be 0.24 when wind was perpendicular to building face with the longest horizontal dimension. Also, the maximum shear coefficients for the same wind direction were found to be 2.48 and 0.52 in $\mathrm{X}$ - and Y-axes, respectively. A similar lowrise building located also in open terrain exposure $(\alpha=0.15)$ with dimensions $\mathrm{L}=61 \mathrm{~m}, \mathrm{~B}=$ $39 \mathrm{~m}, \mathrm{~h}=12 \mathrm{~m}$, i.e. $\mathrm{L} / \mathrm{B}=1.6$ was tested in the current study. The maximum torsion coefficient $\mathrm{C}_{\mathrm{T} \max }$ was 0.22 for the same wind direction as Tamura and et al. [1] study and $\mathrm{C}_{\mathrm{vx}}$ and $\mathrm{C}_{\mathrm{vy}}$ were 2.24 and 0.65 , respectively. Table $4 \mathrm{a}$ summarizes the experimental parameters as well as the evaluated shear and torsion for the two low-rise buildings with similar heights (12 and $12.5 \mathrm{~m}$ ) tested in the current study and by Tamura et al. [1].

More recently, Keast et al. [9] tested a medium-rise building with aspect ratio of $\mathrm{L} / \mathrm{B}=2.0$. The building located in open terrain exposure $(\alpha=0.16)$ and having dimensions $\mathrm{L}=40, \mathrm{~B}=$ 20, and $\mathrm{h}=60 \mathrm{~m}$. The results show that $\mathrm{C}_{\mathrm{T} \text { Max }}=0.2, \mathrm{C}_{\mathrm{vx}}=4.0$ and $\mathrm{C}_{\mathrm{vy}}=1.5$. In the current 
study, a similar medium-rise building with $\mathrm{L}=61 \mathrm{~m}, \mathrm{~B}=39 \mathrm{~m}$ and $\mathrm{h}=50 \mathrm{~m}$ was tested. The building was also located in an open terrain exposure with $\alpha=0.15$. The maximum torsion coefficient $\mathrm{C}_{\mathrm{T} \text { Max }}$ was found to be 0.20 whereas shear coefficients were 3.0 in $\mathrm{X}$ - and 1.25 in Y-direction. Table 4b summarizes the experimental parameters and results for the two medium-rise buildings with heights of $50 \mathrm{~m}$ (current study) and $60 \mathrm{~m}$ (by Keast et al. [9].

Tables $4 \mathrm{a}$ and $4 \mathrm{~b}$ show clearly that the findings of the current study on buildings with aspect ratios of $\mathrm{L} / \mathrm{B}=1.6$ are in line with the reported results for buildings with aspect ratios of 1.4 (by Tamura et al. [1]) and 2.0 (by Keast et al. [9]).

Although there is still a need for more experimental work on buildings with different geometries, the authors believe that their results can be applicable to rectangular buildings with aspect ratios between 1.4 and 2.0, a range covering a lot of building configurations in practice. For such buildings, it appears that a better estimation of the torsional loads could be obtained by applying $75 \%$ of the full wind measured load (i.e. the one that causes maximum shear force) at equivalent eccentricity of $15 \%$.

\section{SUMMARY AND CONCLUSIONS}

The first part of this paper discusses that North American and European Codes and Standards have quite different provisions for wind-induced torsion acting on low- and medium-rise buildings with typical geometries - namely, horizontal aspect ratios (L/B) equal to 1, 2, and 3. For instance, the ASCE 7 [14] applies torsion on low-rise buildings about three times the NBCC [15] values, and about twice the European code values; for medium-rise buildings 
similar significant differences were found. This established the need for the second part of this paper, i.e. to investigate experimentally the wind-induced torsional loads on rectangular buildings. Wind-induced torsion and shears were measured in the wind tunnel for four flatroof buildings having the same horizontal dimensions and different heights ranging from $6 \mathrm{~m}$ to $50 \mathrm{~m}$. In addition, the experimental results were compared with wind load provisions in ASCE 7 [14], NBCC [15] and EN 1991-1-4 [16]. The analysis of experimental results and comparisons with codes/standards demonstrate the following, at least for the specific building cases considered in this study:

a) For low-rise buildings:

- the wind tunnel torsion results are in relatively good agreement with the envelope method in ASCE 7 [14]

- Measured torsion is significantly higher than the provisions of the static method of NBCC [15].

- The wind tunnel results show good agreement with Eurocode.

b) For medium-rise buildings:

- Measured torsion and shear are lower than wind load provisions in ASCE 7 [14] and NBCC [15].

- The wind tunnel torsion results show good agreement with Eurocode; however, shear is overestimated.

Considering the limited number of cases tested in the current study and till more experimental data become available, some recommendations for wind standards and codes of practice could be made: For rectangular low- and medium-rise buildings with aspect ratios 
from 1.4 to 2.0 , a better estimation of torsional loads could be achieved by applying $75 \%$ of the full measured wind load (i.e. the one that causes maximum shear force) at equivalent eccentricity of $15 \%$.

\section{ACKNOWLEDGMENT}

The authors are grateful for the financial support received for this study from the Natural Sciences and Engineering Research Council of Canada (NSERC), as well as le Fonds de Recherche du Québec - Nature et Technologies (FRQNT) and le Centre d'Études Interuniversitaire sur les Structures sous Charges Extrêmes (CEISCE).

\section{REFERENCES}

[1] Tamura Y, Kikuchi H, Hibi K. Quasi-static wind load combinations for low- and middlerise buildings. Journal of Wind Engineering and Industrial Aerodynamics 2003; 91: 16131625.

[2] Melbourne WH. Probability distributions of response of BHP house to wind action and model comparisons. Journal of Wind Engineering and Industrial Aerodynamics 1975; 1 (2): $167-175$.

[3] Vickery BJ, Basu RI. The response of reinforced concrete chimneys to vortex shedding. Engineering Structures 1984; 6: 324-333.

[4] Lythe GR, Surry D. Wind-induced torsional loads on tall buildings. Journal of Wind Engineering and Industrial Aerodynamics 1990; 36 (1): 225-234. 
[5] Boggs DW, Hosoya N, Cochran L. Source of torsional wind loading on tall buildingslessons from the wind tunnel. Proceedings of the Structures Congress, Sponsored by ASCE/SEI, Philadelphia, May; 2000.

[6] Spence S.M.J., Bernardini E., Gioffrè M. Influence of the Wind Load Correlation on the Estimation of the Generalized Forces for 3D Coupled Tall Buildings. Journal of Wind Engineering and Industrial Aerodynamics 2011; 99: 757-766.

[7] Bernardini E., Spence S.M.J., Gioffrè M. Effects of the Aerodynamic Uncertainties in HFFB Loading Schemes on the Response of Tall Buildings with Coupled Dynamic Modes. Engineering Structures 2012; 42: 329-341.

[8] Tamura Y, Kikuchi H, Hibi K. Peak normal stresses and effects of wind direction on wind load combinations for medium-rise buildings. Journal of Wind Engineering and Industrial Aerodynamics 2008; 96 (6-7): 1043-1057.

[9] Keast DC, Barbagallo A, Wood GS. Correlation of wind load combinations including torsion on medium-rise buildings. Wind and Structures, An International Journal 2012; 15(5): 423-439.

[10] Isyumov N, Case PC. Wind-Induced torsional loads and responses of buildings. Proceedings of the Structures Congress, Sponsored by ASCE/SEI, Philadelphia, May; 2000.

[11] Tamura Y, Kikuchi H, Hibi K. Extreme wind pressure distributions on low- and middlerise building models. Journal of Wind Engineering and Industrial Aerodynamics 2001; 89 (14-15): 1635-1646.

[12] Elsharawy M, Stathopoulos T, Galal K. Wind-Induced torsional loads on low buildings. Journal of Wind Engineering and Industrial Aerodynamics 2012; 104-106: 40-48. 
[13] Elsharawy M, Galal K, and Stathopoulos T. Design wind loads including torsion for rectangular buildings with horizontal aspect ratio of 1.6. Journal of Structural Engineering, ASCE 2014; Note 140(4): 1-5.

[14] ASCE 7. Minimum design loads for buildings and other structures. Structural Engineering Institute of ASCE, Reston, VA.; 2010.

[15] NBCC. User's Guide - NBC 2010, Structural Commentaries (part 4). Issued by the Canadian Commission on Buildings and Fire Codes, National Research Council of Canada; 2010.

[16] CEN. Eurocode 1: Actions on Structures - Part 1-4: General actions - Wind actions" Pr EN 1991-1-4, Brussels; 2005.

[17] Davenport AG, Surry D, Stathopoulos T. Wind loading on low-rise buildings: final report on phases I and II. University of Western Ontario, Eng. Sci. Res. Rep., BLWT-SS8; 1977.

[18] Davenport AG, Surry D, Stathopoulos T. Wind loading on low-rise buildings: final report on phase III. University of Western Ontario, Eng. Sci. Res. Rep., BLWT-SS4; 1978.

[19] Standards Australia. Structural Design Actions Part2 Wind Actions. AS/NZS 1170.22011, Standards Australia; 2011.

[20] Stathopoulos T. Design and fabrication of a wind tunnel for building aerodynamics. Journal of Wind Engineering and Industrial Aerodynamics 1984; 16: 361-376.

[21] Van der Hoven I. Power spectrum of wind velocities fluctuations in the frequency range from 0.0007 to 900 Cycles per hour. Journal of Meteorology 1957; 14: 160-164. 
[22] Isyumov N, Poole M. Wind-Induced torque on square and rectangular building shapes. Journal of Wind Engineering and Industrial Aerodynamics 1983; 13: 183-196.

[23] Xie J, Irwin P. Key factors for torsional wind response of Tall Buildings. Proceedings of Structures Congress, Philadelphia, Pennsylvania, USA, Sponsored by ASCE/SEI, May 8$10,2000$.

[24] Zhou Y, Kareem A. Torsional load effects on buildings under wind. Proceedings of Structures Congress, Philadelphia, Pennsylvania, USA, Sponsored by ASCE/SEI, May 8$10,2000$. 
Fig.1. Comparison of torsion load case in wind code and standard provisions for three low-rise buildings with aspect ratios $(\mathrm{L} / \mathrm{B})=1,2$, and 3

Fig. 2. Comparison of torsion load case in wind code and standard provisions for three medium-rise buildings with aspect ratios $(\mathrm{L} / \mathrm{B})=1,2$, and 3

Fig. 3. Building model (scale 1 to 400) and pressure tap location

Fig. 4. Wind velocity and turbulence intensity profiles for open terrain exposure

Fig. 5. Spectra of the longitudinal turbulence component at $\mathrm{Z} / \mathrm{Z}_{\mathrm{g}}=1 / 6$ (Stathopoulos [20])

Fig. 6. Measurement procedure for horizontal wind forces, $F_{X}$ and $F_{Y}$, and torsional moment, $M_{T}$

Fig. 7. Variation of shear coefficients $\left(\mathrm{C}_{\mathrm{VX}}, \mathrm{C}_{\mathrm{VY}}\right)$ with wind direction for building models corresponding to $6,12,25$ and $50 \mathrm{~m}$ heights

Fig. 8. Variation of mean and peak torsion coefficients with wind direction for four different building heights $(6,12,25$ and $50 \mathrm{~m})$

Fig. 9. Horizontal wind force and torsional moment and its equivalent eccentric force

Fig. 10. Comparison of torsional load case evaluated using ASCE 7 [14] and wind tunnel results (Case A: maximum torsion and corresponding shear) 
Fig. 11. Comparison of torsional load case evaluated using NBCC [15] and wind tunnel results (Case A: maximum torsion and corresponding shear)

Fig. 12. Comparison of torsional load case evaluated using EN 1991-1-4 [16] and wind tunnel results (Case A: maximum torsion and corresponding shear)

Fig. 13. Comparison of shear load case evaluated using ASCE 7 [14], NBCC [15], EN 1991-1-4 [16] and wind tunnel results (Case B: maximum shear and corresponding torsion) 


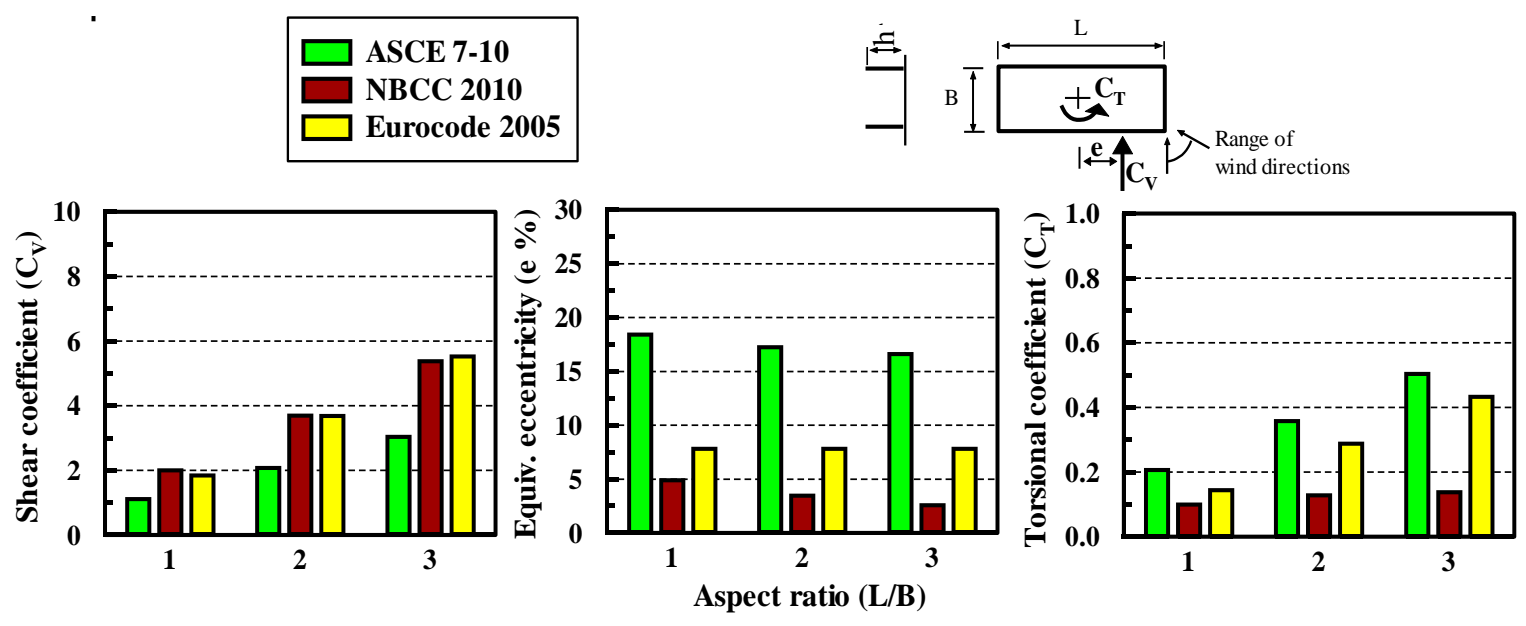

Fig.1. Comparison of torsion load case in wind code and standard provisions for three low-rise buildings with aspect ratios $(\mathrm{L} / \mathrm{B})=1,2$, and 3 


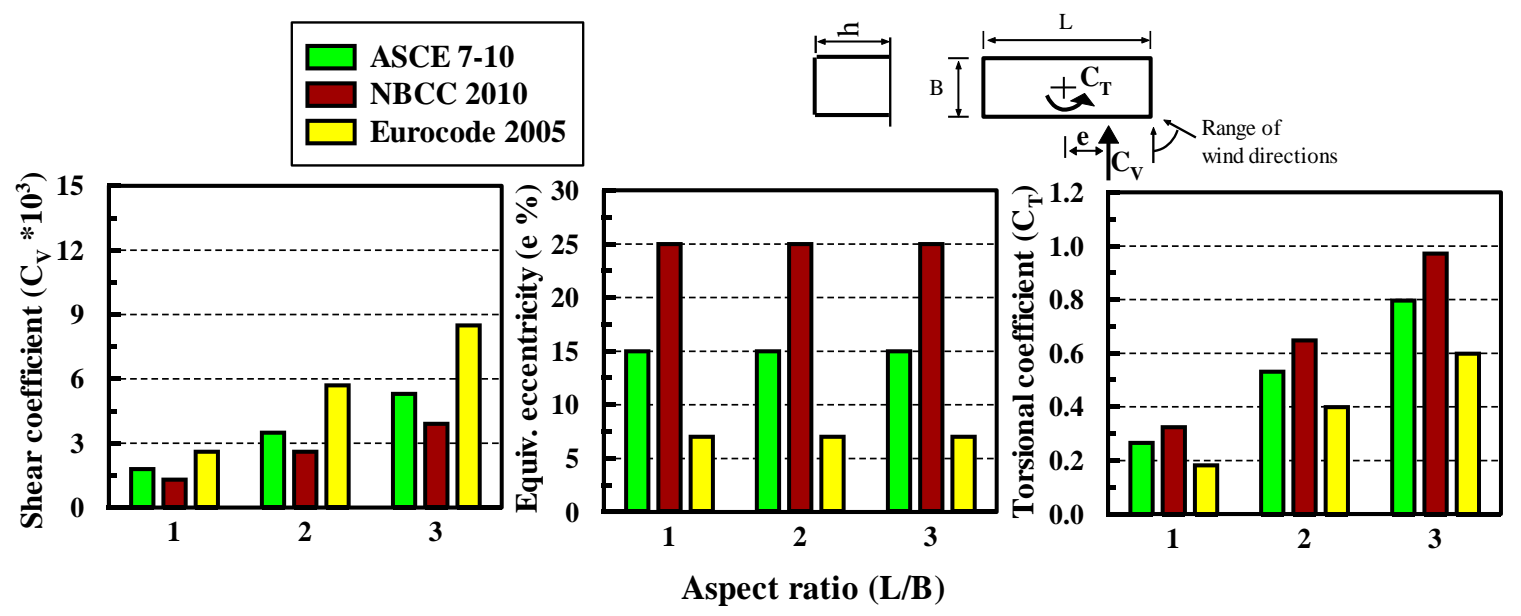

Fig. 2. Comparison of torsion load case in wind code and standard provisions for three medium-rise buildings with aspect ratios $(\mathrm{L} / \mathrm{B})=1,2$, and 3 

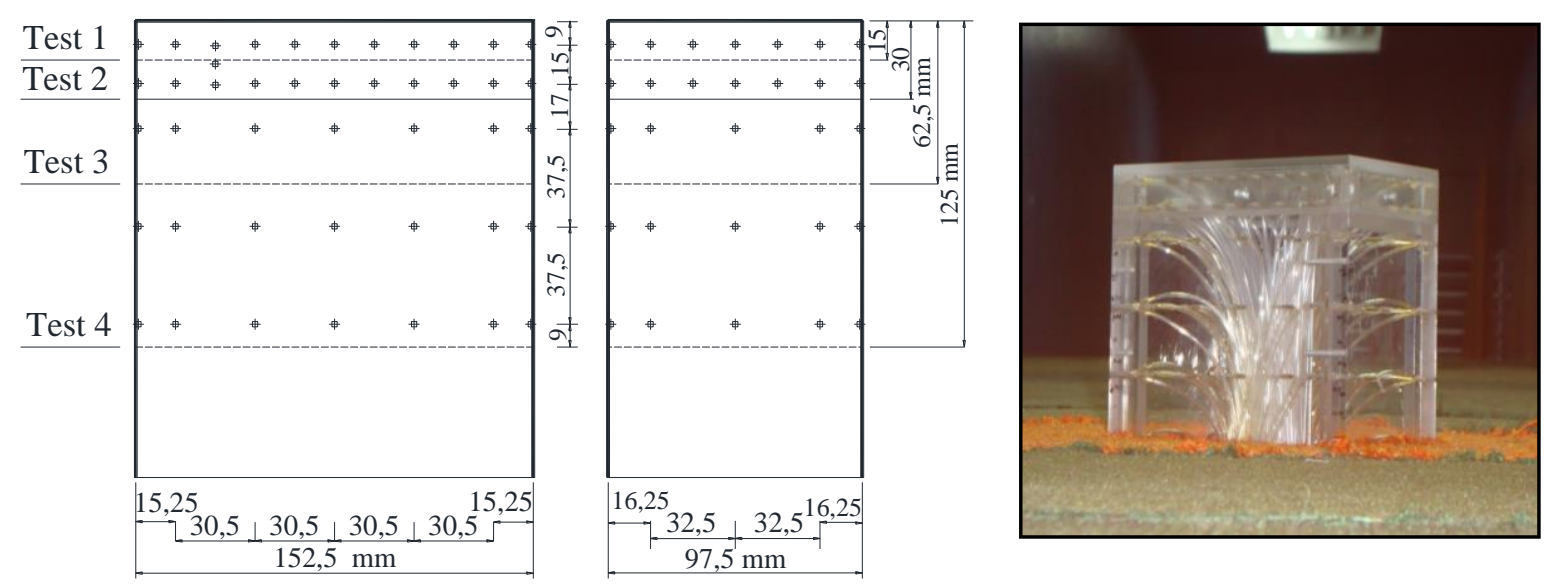

Fig. 3. Building model (scale 1 to 400) and pressure tap location 


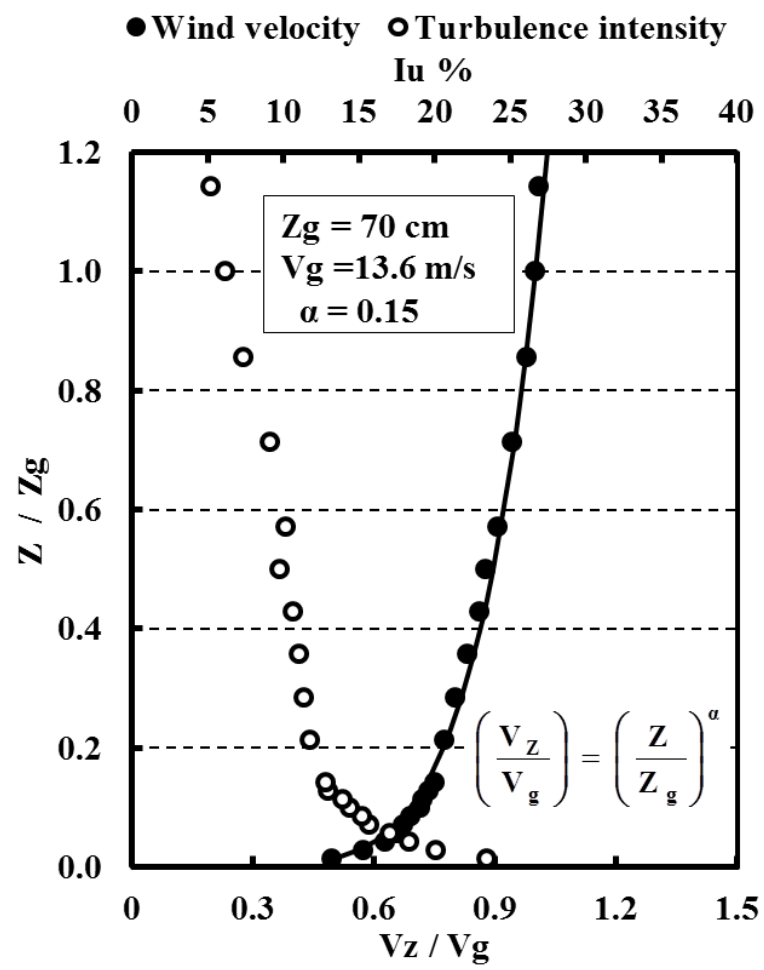

Fig. 4. Wind velocity and turbulence intensity profiles for open terrain exposure 


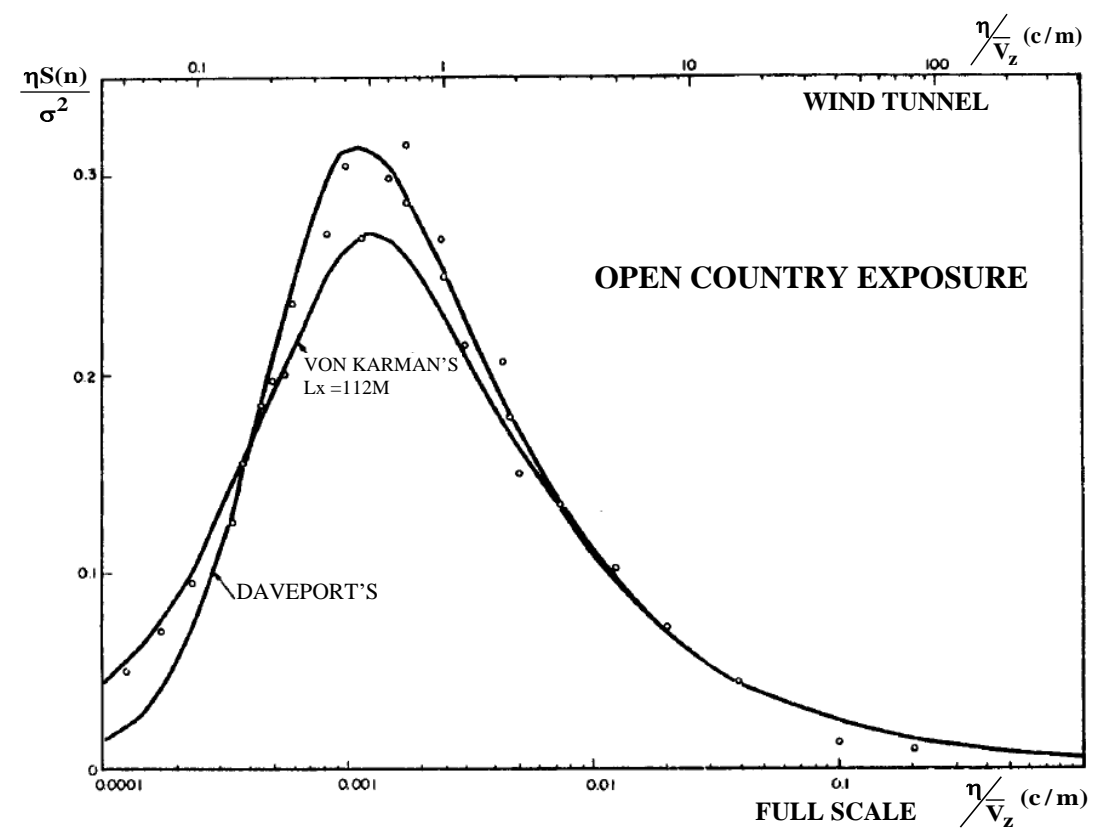

Fig. 5. Spectra of the longitudinal turbulence component at $\mathrm{Z} / \mathrm{Z}_{\mathrm{g}}=1 / 6$ (Stathopoulos [20]) 


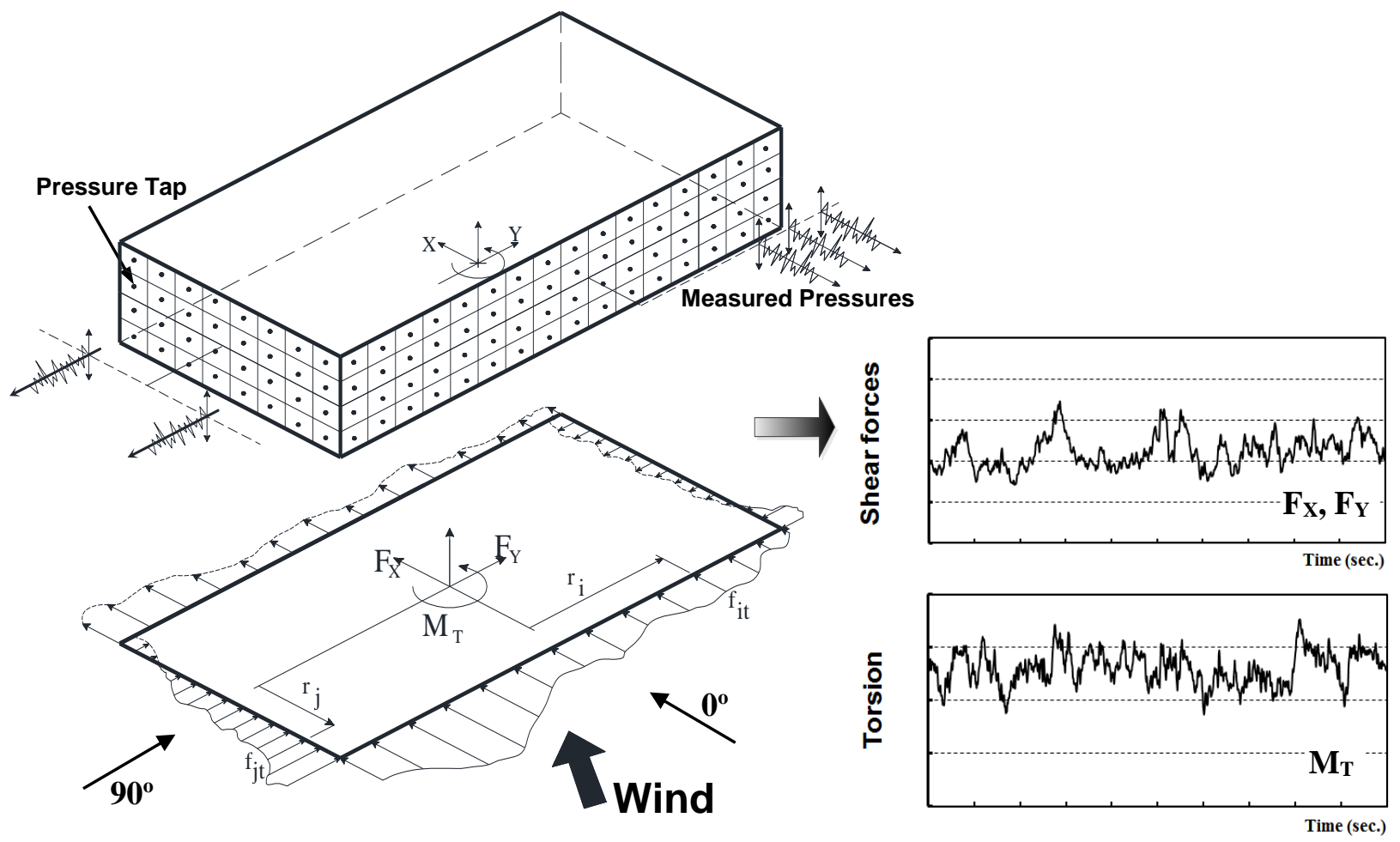

Fig.6. Measurement procedure for horizontal wind forces, $\mathrm{F}_{\mathrm{X}}$ and $\mathrm{F}_{\mathrm{Y}}$, and torsional moment, $\mathrm{M}_{\mathrm{T}}$ 

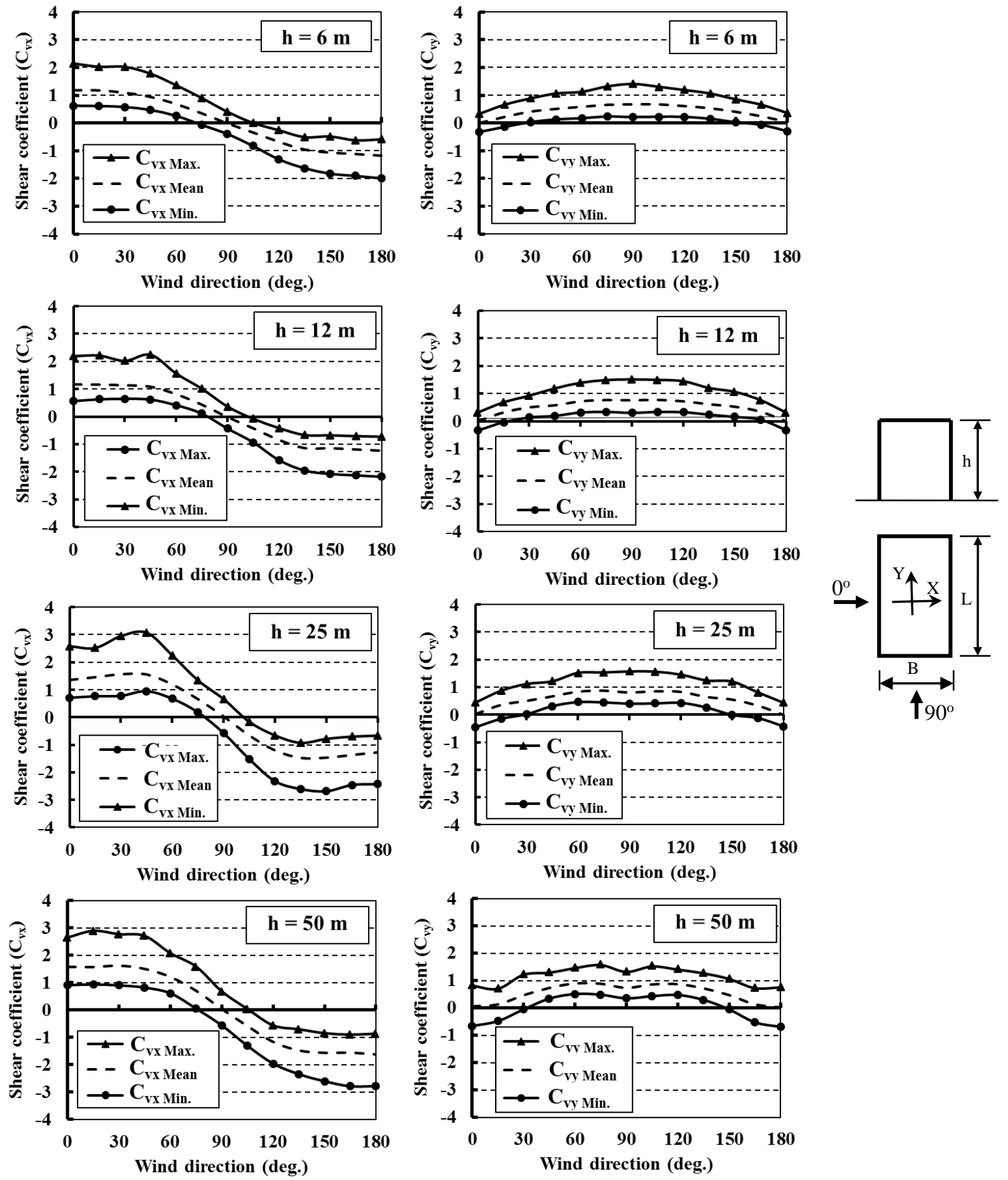

Fig. 7. Variation of shear coefficients $\left(\mathrm{C}_{\mathrm{VX}}, \mathrm{C}_{\mathrm{VY}}\right)$ with wind direction for four different building heights $(6,12,25$ and $50 \mathrm{~m})$ 

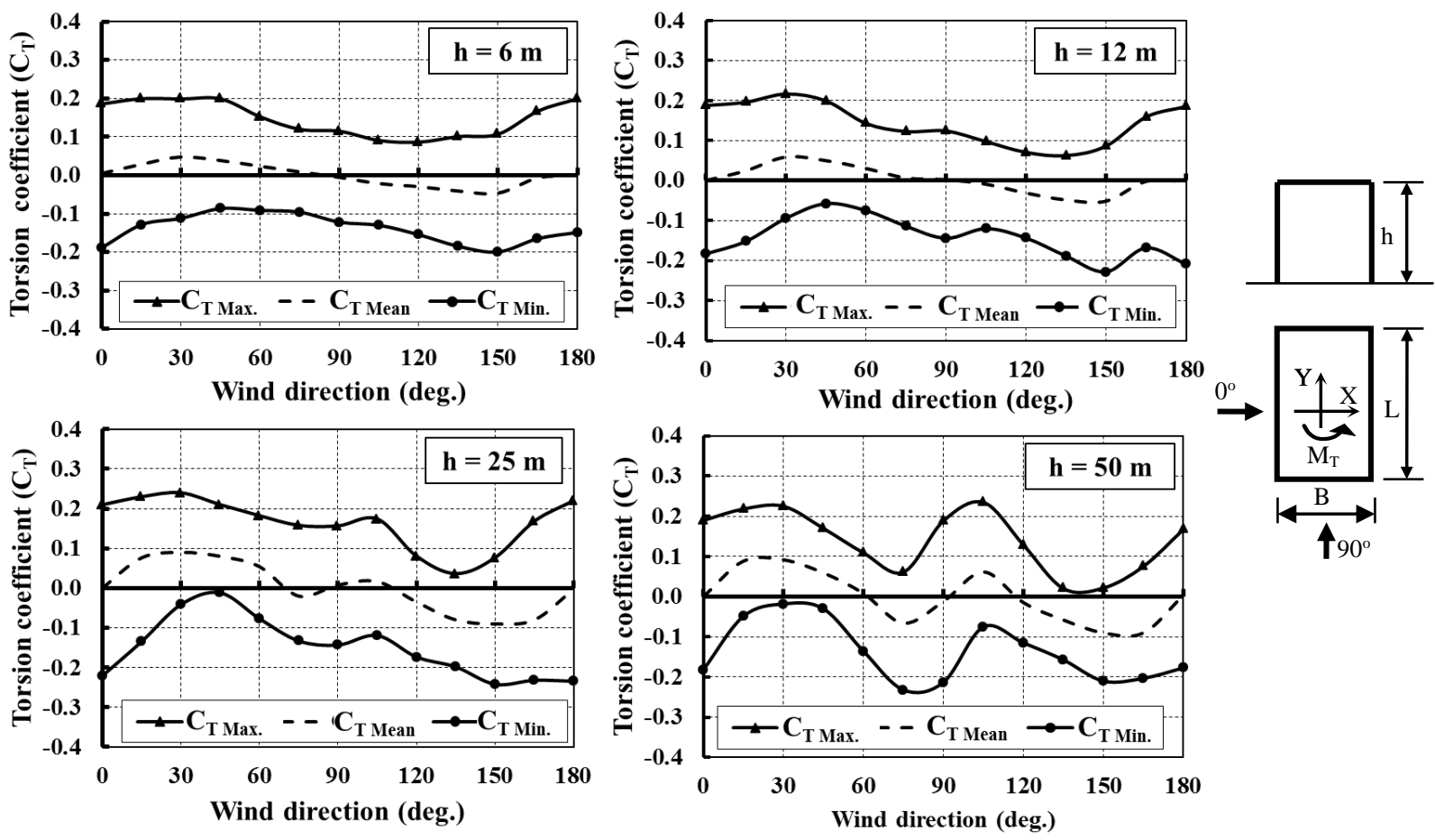

Fig. 8. Variation of mean and peak torsion coefficients with wind direction for four different building heights $(6,12,25$ and 50m) 

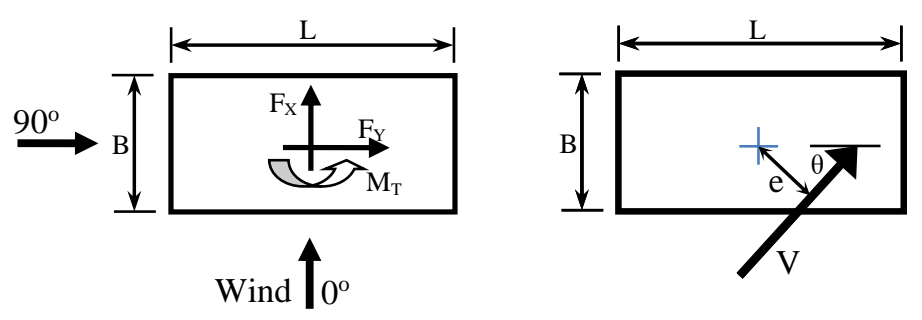

Fig. 9. Horizontal wind force and torsional moment and its equivalent eccentric force 

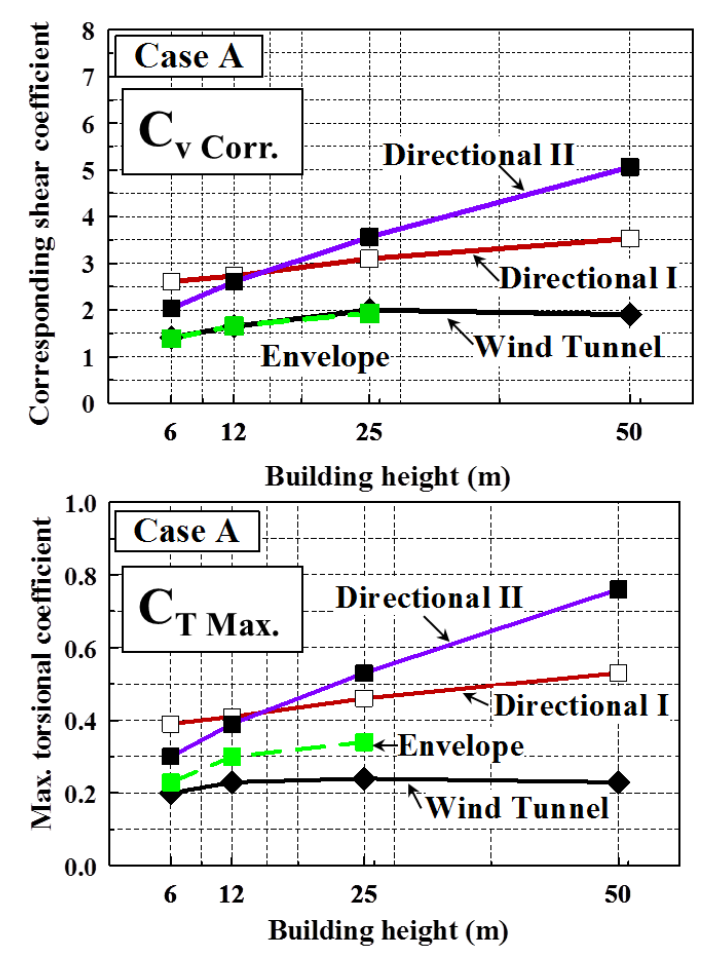
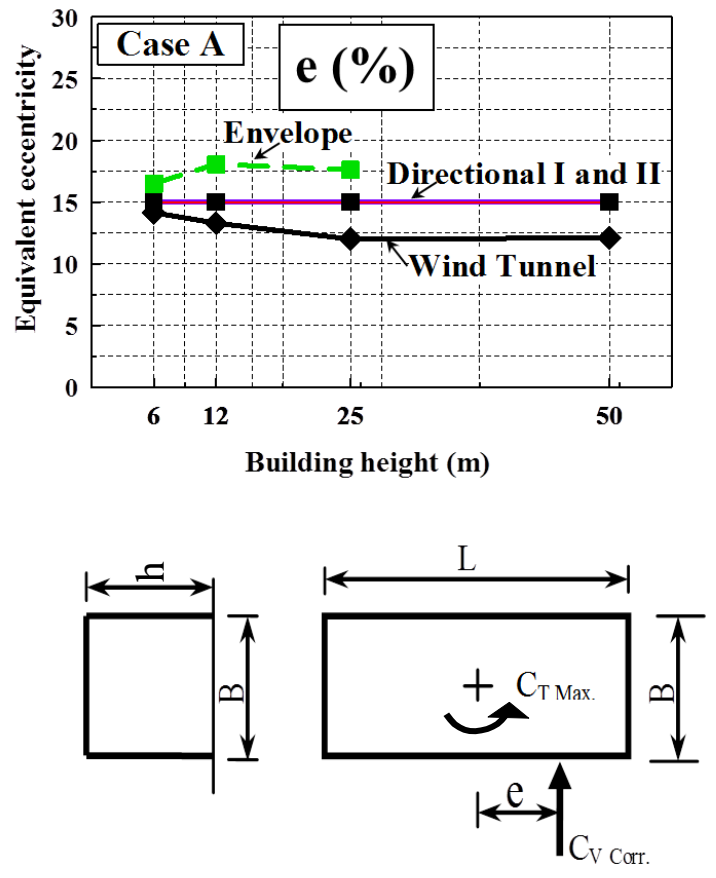

Fig. 10. Comparison of torsional load case evaluated using ASCE 7 [14] and wind tunnel results (Case A: maximum torsion and corresponding shear) 

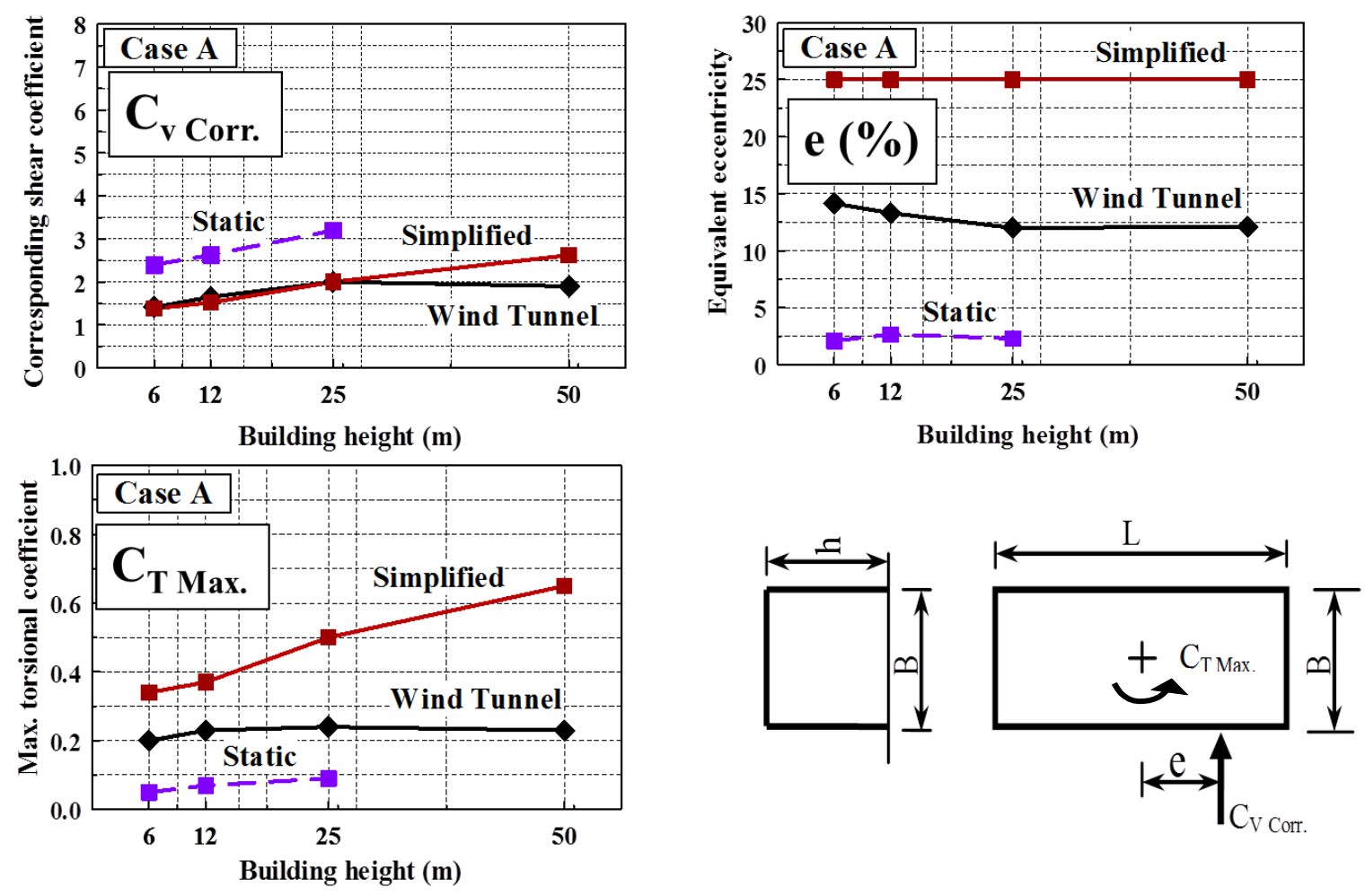

Fig. 11. Comparison of torsional load case evaluated using NBCC [15] and wind tunnel results (Case A: maximum torsion and corresponding shear) 

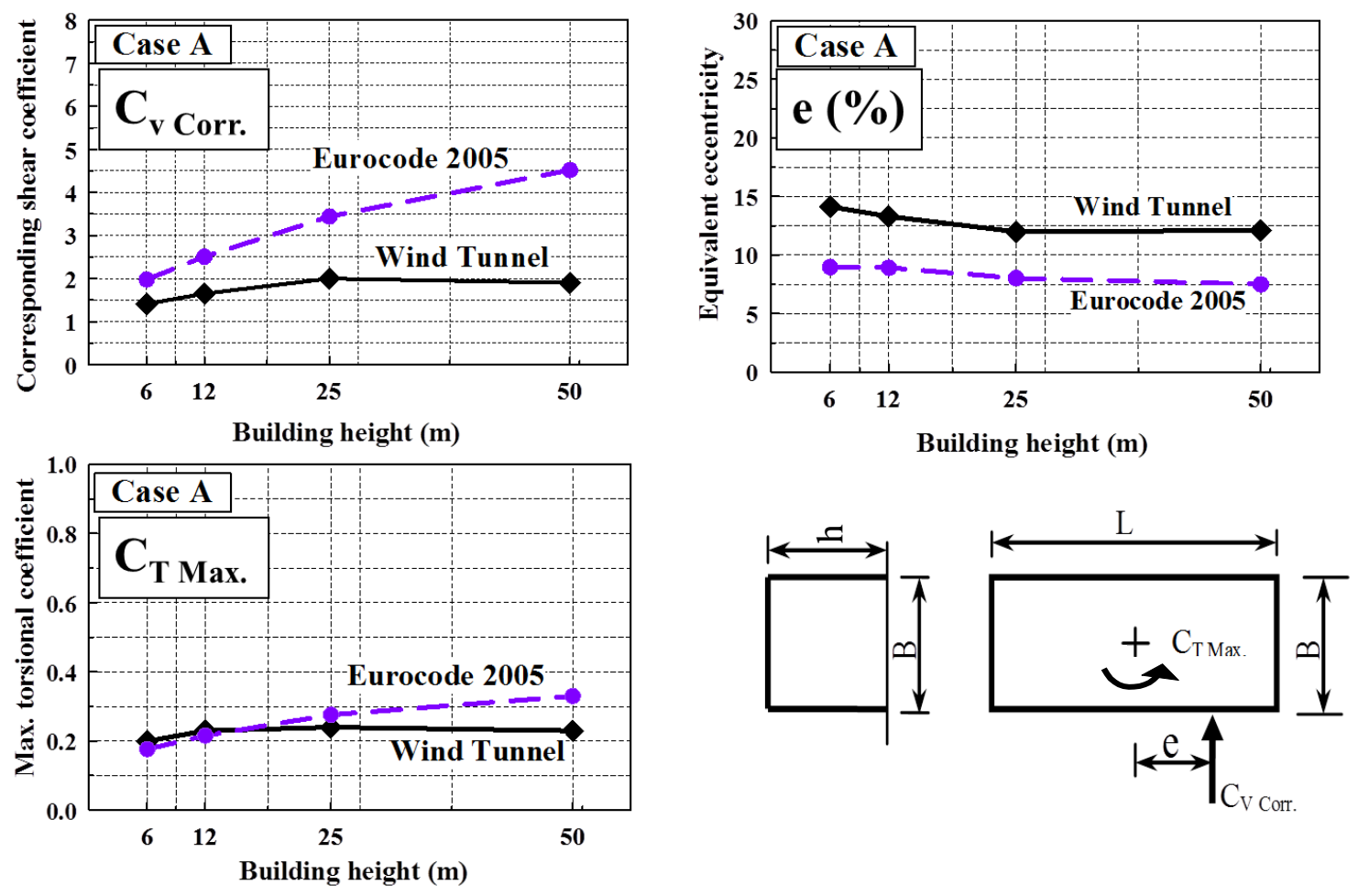

Fig. 12. Comparison of torsional load case evaluated using EN 1991-1-4 [16] and wind tunnel results (Case A: maximum torsion and corresponding shear) 

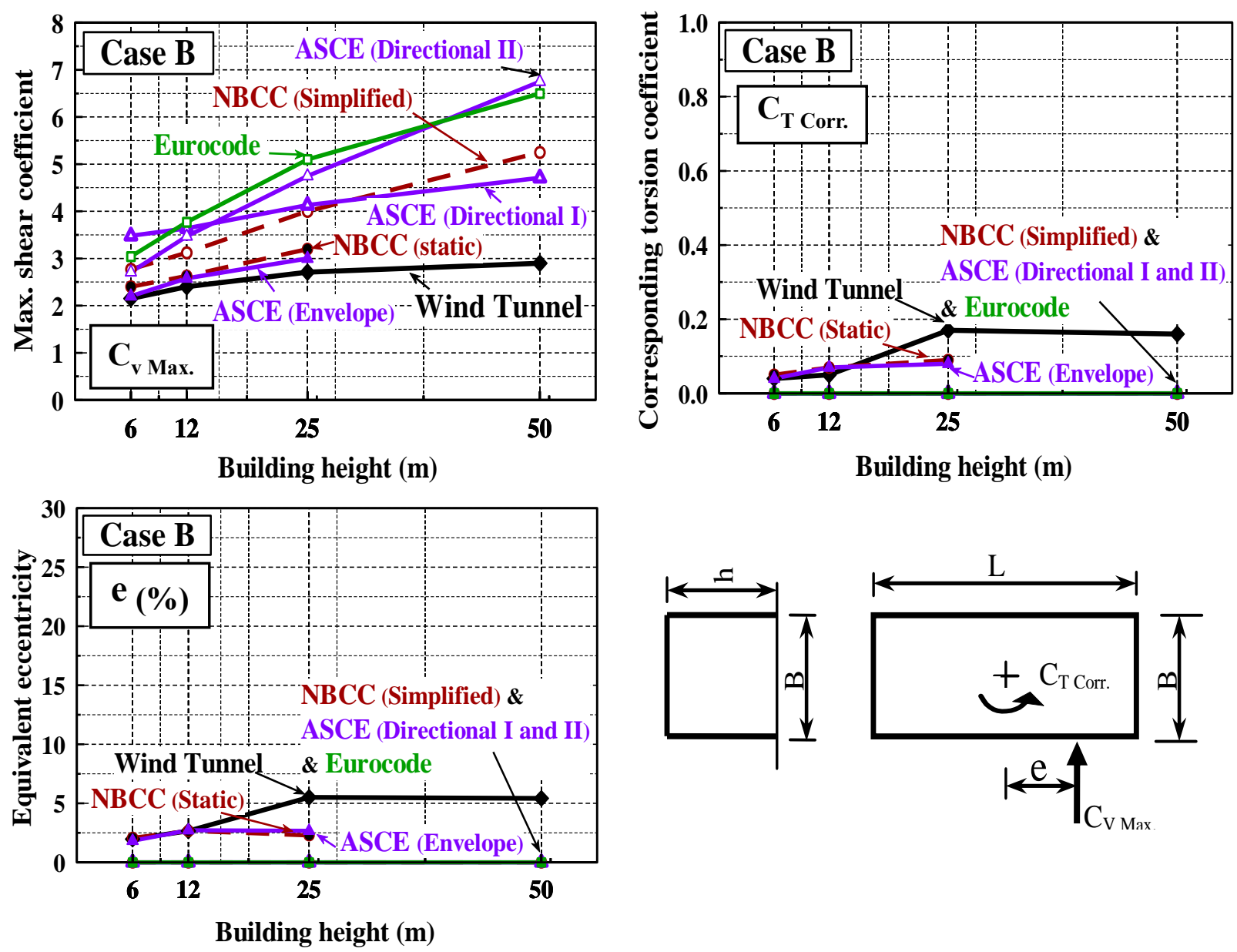

Fig. 13. Comparison of shear load case evaluated by ASCE 7 [14], NBCC [15], EN 1991-1-4 [16] and wind tunnel results (Case B: maximum shear and corresponding torsion) 
Table 1. Model dimensions and building heights tested

\begin{tabular}{lcc}
\hline \multirow{2}{*}{ Building } & \multicolumn{2}{c}{ Dimensions } \\
& Scaled $(1: 400, \mathrm{~mm})$ & Actual $(\mathrm{m})$ \\
\hline Width (B) & 97.5 & 39 \\
Length (L) & 152.5 & 61 \\
Tested heights (h) & $15,30,62.5,125$ & $6,12,25,50$ \\
\hline
\end{tabular}


Table 2. Mean, RMS, and peak factor (P.F) for the critical shear and torsion coefficients

\begin{tabular}{ccccccccc}
\hline $\begin{array}{c}\text { Building } \\
\text { Height }(\mathrm{m})\end{array}$ & \multicolumn{3}{c}{ Torsional coefficient $\left(\mathrm{C}_{\mathrm{T}}\right)$} & \multicolumn{5}{c}{ Shear coefficient $(\mathrm{Cv})$} \\
\hline & $\begin{array}{c}\text { Wind } \\
\text { dir. }\end{array}$ & Mean & RMS & P.F & $\begin{array}{c}\text { Wind } \\
\text { dir. }\end{array}$ & Mean & RMS & P.F \\
\cline { 2 - 10 } 6 & $30^{\circ}$ & 0.05 & 0.04 & 4.25 & $0^{\circ}$ & 1.18 & 0.23 & 1.80 \\
12 & $30^{\circ}$ & 0.06 & 0.04 & 4.00 & $15^{\circ}$ & 1.20 & 0.24 & 1.90 \\
25 & $30^{\circ}$ & 0.10 & 0.05 & 3.00 & $30^{\circ}$ & 1.35 & 0.30 & 1.90 \\
50 & $30^{\circ}$ & 0.09 & 0.03 & 2.50 & $15^{\circ}$ & 1.60 & 0.30 & 1.70 \\
\hline & $75^{\circ}$ & 0.07 & 0.05 & 3.30 & & & & \\
\hline
\end{tabular}


Table 3a. Case A: Maximum torsion $\left(\mathrm{C}_{\mathrm{T} \text { Max. }}\right)$ and corresponding shear $\left(\mathrm{C}_{\mathrm{V} \text { corr. }}\right)$

\begin{tabular}{cccccc}
\hline \multirow{2}{*}{$\begin{array}{c}\text { Building } \\
\text { height }(\mathrm{m})\end{array}$} & \multicolumn{5}{c}{ Wind tunnel measurements } \\
\cline { 2 - 6 } & $\begin{array}{c}\text { Wind } \\
\text { azimuth }\end{array}$ & $\mathrm{C}_{\text {T Max. }}$ & $\mathrm{C}_{\text {V Corr. }}$ & $\theta$ & $\mathrm{e}(\%)$ \\
\hline 6 & $30^{\circ}$ & 0.20 & 1.40 & $89^{\circ}$ & 14.2 \\
12 & $30^{\circ}$ & 0.22 & 1.65 & $72^{\circ}$ & 13.3 \\
25 & $30^{\circ}$ & 0.24 & 2.00 & $77^{\circ}$ & 11.8 \\
50 & $30^{\circ}$ & 0.23 & 1.90 & $72^{\circ}$ & 11.9 \\
50 & $75^{\circ}$ & 0.23 & 1.50 & $24^{\circ}$ & 15.3 \\
\hline
\end{tabular}

Table 3b. Case B: Maximum shear $\left(\mathrm{C}_{\mathrm{V} \text { Max. }}\right)$ and corresponding torsion $\left(\mathrm{C}_{\mathrm{T} \text { corr. }}\right)$

\begin{tabular}{cccccc}
\hline \multirow{2}{*}{$\begin{array}{c}\text { Building } \\
\text { height }(\mathrm{m})\end{array}$} & \multicolumn{5}{c}{ Wind tunnel measurements } \\
\cline { 2 - 6 } & $\begin{array}{c}\text { Wind } \\
\text { azimuth }\end{array}$ & $\mathrm{C}_{\text {V Max. }}$ & $\mathrm{C}_{\text {T Corr. }}$ & $\theta$ & $\mathrm{e}(\%)$ \\
\hline 6 & $0^{\circ}$ & 2.15 & 0.04 & $89^{\circ}$ & 2.0 \\
12 & $15^{\circ}$ & 2.45 & 0.05 & $85^{\circ}$ & 2.7 \\
25 & $30^{\circ}$ & 2.71 & 0.15 & $85^{\circ}$ & 5.5 \\
50 & $15^{\circ}$ & 3.00 & 0.16 & $87^{\circ}$ & 5.4 \\
\hline
\end{tabular}


Table 4a. Comparison with previous study by Tamura et al. [1]

\begin{tabular}{lll}
\hline Experimental variables & Tamura et al. [1] & Current study \\
\hline Wind tunnel technique & $\begin{array}{l}\text { High frequency pressure } \\
\text { integration }\end{array}$ & $\begin{array}{l}\text { High frequency pressure } \\
\text { integration }\end{array}$ \\
Buildings $(\mathrm{m})$ & $\mathrm{L}=42.5 \times \mathrm{B}=30 \times \mathrm{h}=12.5$ & $\mathrm{~L}=61 \times \mathrm{B}=39 \times \mathrm{h}=12$ \\
Aspect ratio $(\mathrm{L} / \mathrm{B})$ & 1.4 & 1.6 \\
Scale & $1: 250$ & $1: 400$ \\
Model dimensions $(\mathrm{mm})$ & $170 \times 120 \times 50$ & $152.5 \times 97.5 \times 30$ \\
Open terrain exposure $(\alpha)$ & 0.16 & 0.15 \\
Wind direction & $\perp$ to building length $(\mathrm{L}=42.5 \mathrm{~m})$ & $\perp$ to building length $(\mathrm{L}=61 \mathrm{~m})$ \\
& & 0.22 \\
Torsional coeff. $\left(\mathrm{C}_{\mathrm{T} \max }\right)$ & 0.24 & 2.24 \\
Shear coefficient $\left(\mathrm{C}_{\mathrm{vx} \max }\right)$ & 2.48 & 0.65 \\
Shear coefficient $\left(\mathrm{C}_{\mathrm{vy} \max }\right)$ & 0.52 & \\
\hline
\end{tabular}

Table 4b. Comparison with recent work by Keast et al. [9]

\begin{tabular}{|c|c|c|}
\hline Experimental variables & Keast et al. [9] & Current study \\
\hline Wind tunnel technique & $\begin{array}{l}\text { A } 6 \text { degree-of-freedom high } \\
\text { frequency balance }\end{array}$ & $\begin{array}{l}\text { High frequency pressure } \\
\text { integration }\end{array}$ \\
\hline Buildings (m) & $\mathrm{L}=40 \times \mathrm{B}=20 \times \mathrm{h}=60$ & $\mathrm{~L}=61 \times \mathrm{B}=39 \times \mathrm{h}=50$ \\
\hline Aspect ratio $(\mathrm{L} / \mathrm{B})$ & 2.0 & 1.6 \\
\hline Scale & $1: 400$ & $1: 400$ \\
\hline Model dimensions (mm) & $100 \times 50 \times 150$ & $152.5 \times 97.5 \times 125$ \\
\hline Open terrain exposure $(\alpha)$ & Calculated 0.16 & 0.15 \\
\hline Torsional coeff. $\left(\mathrm{C}_{\mathrm{T} \max }, 0^{\circ}\right)$ & 0.20 & 0.20 \\
\hline Shear coefficient $\left(\mathrm{C}_{\mathrm{vx} \max }, 0^{\circ}\right)$ & 4.00 & 3.00 \\
\hline Shear coefficient $\left(\mathrm{C}_{\mathrm{vy} \max }, 90^{\circ}\right)$ & 1.50 & 1.25 \\
\hline
\end{tabular}

